\title{
Cultural work place patterns in Academia
}

\section{Cathrine Hasse and Stine Trentemøller}

\begin{abstract}
In Science and Technology Studies (STS) the emergence of scientific knowledge has been studied from a wealth of creative angles. One aspect which has been left relatively unexplored is how universities as work places in- and exclude their members, and how these processes are related to culture. In this article we shall discuss how a focus on cultural clusters of meaning-making practices in scientific work places at universities in different European countries open up for understanding cultural differences in what male and female scientists are interested in and how they wish their knowledge to be acquired and acknowledged. We argue that different work place cultures in- and exclude members in accordance with their different acknowledgements of creative acts, risk-taking, 'useful science' and competition. Moreover, these patterns seem to be connected with a gendered quest for knowledge.
\end{abstract}

Keywords: Science and Technology Studies, gender, organisational culture

It is a well established fact that in all the European countries more women than men leave their career in science in spite of having achieved the same academic qualifications. It is also a well established fact in organisational studies that women in some countries are prevented from pursuing certain careers due to cultural values, traditions and norms. Even so, very little large-scale qualitative research has been done following women and men who leave careers in academia and contrast their cultural values, traditions and norms in relation to who stay on and who leave the university career track within and across national borders.

Instead of relying on an analysis based on general a priori categorizations we shall introducetheempiricallybased construction of three basic work place cultures, which we name 'Hercules,' 'Caretakers' and 'Worker Bees.' The three cultures are characterized by different cultural values, traditions and norms and are constructed along with our methodology of contrasting findings and the particular concept of organisational culture used for this argument. We move on with an example of how competition, creativity and risk-taking work differently in the three different scientific work place cultures and a discussion of how local meaningmaking patterns can in- and exclude male and female researchers for different reasons in the three work place cultures. Next, we will discuss our understanding of gender and how we relate it to exclusion practices in university work place cultures. Lastly, we open up for a discussion of how 
scientific exclusion practices-in what we analytically identify as work place cultures-can be useful in understanding the complex and most often not explicitly enunciated mechanisms behind the actual number of female scientists at university work places as well as the subtle in- and exclusion of cultural values connected to the sustainability of particular scientific epistemologies.

General overviews of scientific career paths have shown, that women's careers in academia are not advancing to the same degree as their male colleagues and that there is little change even though the number of female students keeps rising (European Commission 2005, 2008). In a wider perspective of women in science we find an even greater diversity between top and bottom scores of how many female physicists are employed in academia (European Commission, 2006) ${ }^{1}$. Even though this processes has been described with the metaphor of a 'Leaky Pipeline' women are not only pushed out of academia, but more generally choose better work lives elsewhere (Svinth, 2008: 41).

The international research project UPGEM (Understanding Puzzles in the Gendered European Map) ${ }^{2}$, which looked specifically at the discipline of physics, found this and another puzzling fact confirmed: namely that even though women do not 'climb ladders' to the same extent as their male colleagues anywhere in Europe, considerable differences in the proportion of female professors are found in the different countries. In the five European countries partaking in the project we found the highest proportion of female physicists in Italy where women constitute $33 \%$ of the associate professors and $23 \%$ of the full professors. In Denmark we found the lowest number of female physicists who constitute $10 \%$ among the associate professors and only $3 \%$ of the full professors. Universities as work places thus show a pattern of gender differences, which apparently are connected with differences in national cultures.

In a quantitative project studying how national cultures influence work places within the same international cooperation (IBM was used as a case), Geert Hofstede found that national cultures differ in how they for example estimate traditionally male or female values, power relations, avoidance of uncertainty, individualism and group work (1980). The approach and methods used by Hofstede have, however, been severely criticized for being superficial constructs building on a priori assumptions and prejudices. Cultural analysis requires methods that can capture the richness and also the internal diversity of national practices; surveys based on a priori categorisations like Hofstede's may lead to a reductive and a single-cause type analysis (McSweeney, 2002). The main research question remains, however, why the gender pattern of employment differs from country to country. Is this pattern originating in national cultures influencing who can practice science at scientific work places like universities? Or is the gender pattern embedded in the scientific practice of doing physics research in itself in ways which are more exclusive for female physicists? In other words, how do culture, science and gender emerge and create each other?

As noted in the introduction, the overall objective of the UPGEM project was to understand why we find cultural diversity in the proportion of female physicists employed at universities across Europe. The project has formed its huge qualitative empirical material in a predominantly male dominated physics research environment, which in general has attracted few women. Even so, we find differences in how many women have engaged in physics research, and we find differences across national cultures in terms of men's and women's 
research interests and possibilities to unfold these interests. It is partly through this research (combined with a former study of university cultures in Denmark) we became aware that universities as work places not only in- and exclude gendered researchers but also display a rather coherent pattern of gendered research fields and scientific knowledge across work place cultures as well as national cultures.

This qualitative approach to studying the emergence of scientific knowledge is well established within the field of Sociology of Science and Knowledge (SSK) and its offspring Science and Technology Studies or Science, Technology and Society (both STS).

The combined efforts to understand the processes behind scientific knowledge are manifold and have included the influence of technology on scientific knowledge (and vice versa) (e.g. Knorr Cetina, 1999; Ihde, 2002), the entanglement of human and non-human actors in the production of knowledge (e.g. Latour 2005), the changing role of the concept of knowledge as demarcation lines between disciplines and society are dissolving (e.g. Nowotny et al., 2001, Gibbons et al., 1984, Rouse, 1992). It remains a topic of interest how science as culture and science embedded in national cultures can influence the gender of those who practice science. Throughout the debates gender perspectives have been discussed as the general relation between gender, science and technology (e.g. Haraway, 1997, Barad, 2001), situated knowledges (Haraway, 1991), feminist philosophy of science (e.g. Harding, 1986, Longino, 2002), general historical masculinist tendencies in science (Merchant, 1989) and the exploitation and lack of acknowledgement of female researchers or (increasingly) on the increasing or declining number of female scientists within disciplines or different national settings (e.g. Etzkowitz, Kemelgor and Uzzi, 2000). Cultural diversity has been invoked in analysis of the differences in how science is practiced and understood in different national cultures and indigenous cultures (e.g. Traweek 1992, 1988, WatsonVerran \& Turnbull, 1995) and feminist and postcolonial science studies have argued that science is a culturally embedded practice influenced by "cultural histories, interests and values" (Harding, 2006: 154). The arguments in postcolonial studies have, however, rarely tried to look for cultural diversity within what is generally defined as 'western' sciences.

What we contribute to these discussions is a perspective of universities as organisational cultures, i.e. work place cultures, which in- and exclude gendered practitioners and possibly also gendered preferences for scientific work in relation to local patterns of meaning, supported by European national cultural histories. Work place cultures we define as the practiced place (what people do), whereas organisational culture refers to the cultural organisational aspects (e.g. traditions, dress-codes, arrangement of offices etc.).

\section{Emerging work place cultures}

This section describes the analytical process that led us to bring together the entire data material as examples of three different but interrelated ideal type work place cultures.

The project conducted 208 qualitative interviews $^{3}$ at more than 20 universities in five European countries, and transcriptions of all interviews were uploaded to the analysis programme Atlas.ti. Approximately half of our informants look back on their career in academia from their present position as outsiders to a university-based position (we named these "leavers" even when the choice to leave was voluntary), while the other half talk from their position as "stayers," that is, scientists who are still active in physics research in academia. ${ }^{4}$ Our 
broad definition of a leaver is a physicist who has begun or finished a Ph.D. in physics but has left physics research in academia in his or her home country. By including interviews with leavers in the empirical data material, UPGEM adds a hitherto unexplored dimension to the understanding of gendered career paths in academia as it allows the project to obtain a unique insight into the local context from an external retrospective perspective. Moreover, we get the opportunity to contrast statements from stayers and leavers about identical topics within the same national cultural context (Hasse \& Trentemøller, 2009, 3).

In processing the interviews analytically, statements were selected as quotations and labeled with the relevant thematic code(s), as for instance 'competition', 'family' or 'discrimination. In the first analytical phase, the interviews were analyzed nationally, i.e. the Estonian interviews were coded by the Estonian researchers, the Polish interviews by Polish researchers and so on. In all, the collective trans-national Atlas. ti database comprised more than 16,000 quotations. The local national analyses resulted in five individual, yet comparable, reports presenting interpretations of inand exclusion mechanisms of the scientists in the given country. The specific reasons for leaving are discussed in these national reports (Hasse, Sinding \& Trentemøller, 2008). Many themes and explanations were recurring, yet we also found out that some themes were salient in one analysis but downplayed or absent in another, and that the reasons for leaving physics were argued for in different manners which pointed towards local rather than cross-cultural explanations.

To reach a better understanding of these subtle mechanisms of exclusions and see possible transnational convergence and/or contrasts, the Danish team of researchers read and analyzed further the entire data material in the second phase of the analytical process. Thus, the transverse analysis draws on the five national reports and the entire data-material in a meta-perspective.

Despite our focus on gender, we decided to disconnect identity labels revealing the gender and nationality of the individual interview in the second phase of analysis. The purpose of this exercise was to limit the risk of coming to certain conclusions based on a priory categorizations and possible gender biased pre-understandings and give ourselves the possibility of being surprised. Subsequently, we extracted quotations on the basis of a code, e.g. 'competition', and when relevant we attached 'competition' to non-coded statements an extracted these too. The aim was to discover patterns of convergence and contrasts across the entire data material. These patterns are based on clusters of semantically similar statements that are in contrast to other clusters of statements. This could for instance be clusters of statements from physicists who are oblivious to competition at work, statements from physicists who find competition at work productive and invigorating or statements that describe a negative attitude to competition.

What we looked for, using this approach, was overall 'patterns of meaning' behind patterns of in- and exclusions. Culture is in this perspective not just 'national culture' nor simply "webs of meaning the cultural actors themselves have spun" to refer the anthropologist Clifford Geertz' famous Max Weber inspired definition of culture (Geertz, 2001: 17), but organizations of cultural webs of meaning, which can be argued to have directional force for actions and thus potentially exclude actors who challenge the generally accepted cultural meaning systems (Holland and Quinn, 1987; Strauss \& Quinn 1997). These patterns can manifest themselves as actions or spoken discourse (which is also a form of historical action). Even though the general cultural effects of spoken words and actions may escape 
individual interlocutors and actors it does not follow that intentions are irrelevant to an analytical understanding of actions and spoken words (Strauss, 1992, 5). Shared cultural models can be defined as: "learned internalized patterns of thought-feeling that mediate both the interpretation of ongoing experience and the reconstruction of memories" (Strauss, 1992:3). These patterns, i.e. cultural models, have directional force and motivate actions and spoken words while reinforcing and being reinforced by the words and actions.

Though there is no causal relation between the models, they will, being self-evident, normally not contradict nor challenge each other but form intelligible connections. These shared cultural models reinforce each other across models and thus form patterns of interconnected meaningmaking, which we describe as "clusters of cultural models", (Hasse \& Trentemøller, 2008). To identify cultural patterns of meaning, the models cannot be analysed separately but must be seen in relations.

We organized matching quotations to identify 'clusters' of cultural models (Hasse \& Trentemøller, 2008) $)^{5}$. By contrasting the identified clusters of cultural models, a pattern emerged reflecting three types of work place cultures with their own characteristics (irrespective of nationality, sub-discipline, gender etc.). ${ }^{6}$ This method of contrasting is useful for identifying how self-evident exclusion patterns in one cluster of connections, become self-evident inclusion patterns in another (Hasse \& Trentemøller, 2009). The quotes we ordered in contrast to each other were not analysed in their national context (particular physics institutes in Finland, Denmark, Italy, Poland or Estonia) and statements from the same person could be placed in different clusters. By taking quotes out of their gendered, national, and institutional actual settings, we can cultivate our non-a priori formed understanding of the subtle and complex directional forces at work in everyday practices. $^{?}$

The contrasted characteristics reflect, among other things, different values, norms and traditional codes of conduct within in physics as culture and point, thus, to the implicit ideal type definition of a 'good employee/scientist' in each culture type. ${ }^{8} \mathrm{On}$ the basis of their characteristics, we named the three work place cultures: Hercules, Caretakers and Worker Bees. Each culture consists of clusters of cultural models, which form coherent patterns as models for behaviour at the work place. However, in the further analysis these models for behaviour identified in the analytical process, can also be argued to become models of how real-life individual interlocutors should and would react to perceive values and traditions connected with the local scientific practice. Once these meaning patterns become models for behaviour, they can be used as understanding the local cultural self-evident measuring sticks for culturally informed actions (Hasse \& Trentemøller, 2009). People might feel excluded when their stated words and executed actions do not fit or might provoke generally shared values and norms connected with the cultural models. This is a subtle process which over time might persuade a researcher to leave a career in physics.

The next step in the analytical process was to disclose the nationality and gender of the physicist behind each quotation and correlate this with our analysis of gender in general. When nationality and gender are replaced, the models for cultural thoughtfeeling become models for actual behaviour in work place cultures.

Subsequently, we were able to make the argument that the three work place cultures provide men and women with different opportunities for developing their career, because gender and science are ascribed different meanings in each of the three 
culture types and that work place cultures are supported by national cultures.

Naturally, there is much to be said about the vast and complex data material and our new approach. Yet, in this article we will focus on the three trans-national work place cultures in our discussion of primarily the Danish data versus the findings in the other UPGEM countries. ${ }^{9}$

\section{Science in work place cultures}

The above-mentioned notion of culture we have used in the UPGEM project to study how university cultures differ from the ones normally used in organizational studies. The field of organizational culture has generally focussed on culture as something organizations have or are (Smircich, 1983) often based on management decisions and the values, norms and traditions initiated by founders and managers (Schein, 2004). The field has in general been criticized for a lack of methodology and basic empirical research (Alvesson \& Berg, 1992) and a focus on consensus rather than fragmentation (Martin, 2002). In empirical studies of organisational cultures the focus has often been on symbols and rituals rather than attempts to analyse everyday lives related to the work place. Our approach thus diverges from the general field of organisational culture by focussing on what informants tell us about what they do and how these doings can be related to what we analytically find informants perceive, but not necessarily

Table 1 Patterns of meaning in the three work place cultures

\begin{tabular}{|c|c|c|c|}
\hline & HERCULES & CARETAKER & WORKER BEE \\
\hline $\begin{array}{l}\text { Work } \\
\text { relation }\end{array}$ & $\begin{array}{l}\text { Devotion to physics. } \\
\text { No intersection of } \\
\text { family with work. }\end{array}$ & $\begin{array}{l}\text { A healthy work life balance is } \\
\text { prioritized. Social concern. }\end{array}$ & $\begin{array}{l}\text { Research is } 9-5 \text {. Private } \\
\text { life and work life clearly } \\
\text { divided. }\end{array}$ \\
\hline $\begin{array}{l}\text { Work place } \\
\text { identity }\end{array}$ & $\begin{array}{l}\text { Very individualistic. } \\
\text { Praise initiatives, } \\
\text { creativity. No room for } \\
\text { weakness. }\end{array}$ & $\begin{array}{l}\text { Group oriented with focus } \\
\text { on social ties. Team can help } \\
\text { the weak but maybe limit the } \\
\text { creative work if the group } \\
\text { demands it. }\end{array}$ & $\begin{array}{l}\text { Work alone and keep to } \\
\text { one self. Focus on the given } \\
\text { task + work regulations and } \\
\text { conditions. }\end{array}$ \\
\hline Competition & $\begin{array}{l}\text { One-on-one open and } \\
\text { hidden competition is } \\
\text { encouraged. All means } \\
\text { are employed. } \\
\text { Strategic thinking is } \\
\text { necessary. }\end{array}$ & $\begin{array}{l}\text { In-group competition is } \\
\text { unacceptable-only group vs. } \\
\text { group. The group defines the } \\
\text { means of competition. }\end{array}$ & $\begin{array}{l}\text { Uninterested \& somewhat } \\
\text { scared of competing- } \\
\text { requires extra effort. } \\
\text { Competition only at top- } \\
\text { level. }\end{array}$ \\
\hline $\begin{array}{l}\text { Power } \\
\text { structure }\end{array}$ & $\begin{array}{l}\text { Anti-authoritarian } \\
\text { tendencies challenge } \\
\text { those with power } \\
\text { through individual } \\
\text { hidden power games. }\end{array}$ & $\begin{array}{l}\text { Seemingly flat structure but } \\
\text { entanglement of team/group } \\
\text { and the leader's power; the } \\
\text { leader use power to promote } \\
\text { and protect the group. Young } \\
\text { must earn membership are } \\
\text { exploited by elder group } \\
\text { members. }\end{array}$ & $\begin{array}{l}\text { Clear and formal hierarchy. } \\
\text { Distant but strong leader; } \\
\text { one-man institutes, with } \\
\text { many workers who can be } \\
\text { replaced. }\end{array}$ \\
\hline Gender & $\begin{array}{l}\text { Being woman/mother } \\
\text { is used negatively } \\
\text { in competition. } \\
\text { Gender overshadows } \\
\text { competency-leading } \\
\text { to cases of sexual } \\
\text { harassment. }\end{array}$ & $\begin{array}{l}\text { Group loyalty comes before } \\
\text { gender (and competency). } \\
\text { Few cases of conflict } \\
\text { including sexual harassment. }\end{array}$ & $\begin{array}{l}\text { Absence of competition } \\
\text { makes gender unimportant. }\end{array}$ \\
\hline
\end{tabular}


accept, as the cultural values, norms and traditions of the everyday life at the work place.

In an STS-perspective, the relation between academic work place culture and laboratory culture has often taken a different shape with its focus on how physical environments shape conditions for knowledge (e.g. Knorr Cetina, 1999, Pickering 1992). However, the concept of culture itself tends to refer to some kind of consensus rather than a concept to be explored in its own right.

An important aspect of our definition of culture is that it allows for the method of culture contrast, i.e. the construction of work place cultures as empirically inspired/ based analytical tools, which we can use to explain actual in- and exclusions from scientific practice. Put differently, the three work place cultures function as an analytical tool to understand: "what makes people think-feel-talk-mean-act in ways that everyone in their group takes to be normal" (Traweek, 1992: 440). However, we would like to add that although people may take it to be normal or self-evident to 'think-feeltalk-mean-act' in a certain manner, they will feel, and in reality be, excluded from the work place if they are unable to identify or accept at least some of the values and norms of the given work place culture.

Table 1 illustrates some of the salient elements in the three culture types we created through the method of culture contrast. Five central parameters are decisive for the scientist's level of engagement in physics, degree of involvement in their social and societal surroundings and the degree of importance of gender in each of the scientific cultures.

What is admired in the Hercules culture is to see research as a passion. It is in this culture we find the strongest underlining of both creativity and competition. Social relations to people who are not relevant for physics research and societal demands are seen as interrupting elements, which takes the focus away from the research, which takes place in a closed 'physics bubble'. Each researcher has to signal selfconfidence and a willingness to take risks and fight for his or hers research ideas in a very egoistical manner. Consideration of other people's weaknesses falls back on you and is not admired. What is admired it stubbornness and a willingness to fight for being acknowledged as the most creative researcher most likely to win a Nobel Prize. In this work place culture, leadership invites researchers to local one-on-one fights or at least accepts fighting as a necessary precondition for getting the best research. Hercules is anti-authoritarian and if it brings victory closer, i.e. being accepted as the most innovative and best researcher, he will acknowledge hidden competition and power-games using strategic thinking. When we replaced gender and nationality in the clusters of quotations we found that, in general, the female researcher expressed that they were most uncomfortable in this work place culture, which was the predominant in the Danish work place environment where we also found the fewest women.

In the Caretaker culture, innovative research work is seen as extremely important. Yet, contrary to the Hercules culture, research should not proceed at any prize rather it must fit with the social relations of the work place. Science should interact with society, be responsible and useful, and not take unnecessary risks. Loyalty to the group members is highly valued in this culture. In the Caretaker culture, social relations with people outside of physics are appreciated-just as the social relations inside the research group. This can have the effect that radical innovations, which a Hercules would be admired for, can be subdued by the group in a Caretaker 
culture. On the other hand, the group is both supporting the not so innovative as well as innovative group members, which are under attack from other physicists. Competition is between, not within, groups. Thereby innovative ideas, which might have lost the battle in a Hercules culture, may find room for slow development and maturity in the Caretaker culture. When we replaced gender and nationality in the clusters of quotations we found that, in general, the female researcher expressed that they were rather comfortable in this type of work place culture, which was the predominant in the Italian work place environment where we also found the most women. ${ }^{10}$

\section{The Worker Bees}

In the third work place culture, Worker Bees, we find the complete opposite of the antiauthoritarian attitude so highly respected in the Hercules culture. Here research is seen as wage labour. Worker Bees maintain a sharp demarcation between private and public life at the work place and it is not popular to bring concerns for the family or societal concerns to work. A Worker Bee does his job and avoids his colleagues. Therefore, competitions are not only shunned, for many Worker Bees it is non-existent as a factor in work life. The Worker Bee laments bureaucracy, but focuses on the given work tasks and keeping working hours not too long rather than on being innovative. When we replaced gender and nationality in the clusters of quotations we found that, in general, neither male nor female researcher expressed any expectations of work place norms and values, which challenged, which was predominant in the Estonian and Polish data-material. Even though we found some of the worst examples of work place environment, also for female researchers, we did not find that this led to a lack of women in physics. ${ }^{11}$

\section{Cultural diversity in ways of competing}

The notion of competition is a general recurrent topic in the physicists' accounts of the scientific environment and everyday working life and can be further explored as an example of our analysis of the work place cultures. From our data, two types of competition emerge: open and hidden competition. The term 'hidden competition' was coined by the Danish team in the process of analysing their empirical data for the Danish National Report (Hasse, Sinding \& Trentemøller, 2008). Hidden competition typically occurs on a personal level, i.e. individual colleagues competing against each other within a research group. To some extent, hidden competition seems to be more common in work place cultures where the notion of self-emphasis plays a decisive role in obtaining status. Inherent in the acceptance of flaunting one's intelligence lays a tendency to downgrade or ridicule one's competitors by using means that lies outside the area of skills and competency. Such means may for instance include stealing research results, obstructing research work or putting colleagues' lack of knowledge on display at lectures.

Open competition mainly occurs between research groups, fields or disciplines or even between nations. It is characterised by work procedures and practices where colleagues show group orientation by e.g. planning strategies jointly and where all know who is competing for what against who and with which means. In comparison to hidden competition, open competition is typically described as a constructive and motivating factor.

In the UPGEM data, the Hercules culture is characteristic of being the most competitive and accepts hidden as well as open competition. Competitive situations are typically encouraged by the elders because fierce personal battles are believed to be the best selection mechanism, i.e. 
the best way to ensure that only the most able will win (Hasse \& Trentemøller, 2008: 80-81). Because a Hercules physicist does not shun hidden competition, data from work places where this culture type is the dominant holds a number of examples of the loosing part not being aware of his or her involvement in a personal fight before they lost the battle. Moreover, as Hercules physicists do not organize themselves in groups, such fights are always individual and personal.

Danish Female: [I]t's everybody against everybody and you therefore have to think very strategically and notice what your colleagues do and what it means when they do this and that and what sort of hidden ulterior motive they have when they do so and so. And that's a bit hard but that's the way it is. (ibid., 78) 12 $^{12}$

As indicated by the above quotation, it is questionable whether the physical science rewards the most able or skilled physicists by employing this cultural norm; indeed, one will not survive a Hercules culture on academic skills alone. Though we do have examples of female Hercules types, a Hercules fighter is typically powerful or ambitious man.

It is important to be able to think strategically as all means-including gendercan be used in competition. Consequently, gender may come to overshadow skills or competency, as is the case when sexual harassment against women is practiced and silently accepted in the Hercules culture:

\footnotetext{
P32, Male: (...) His form is always an attacker. He is very direct and very firm, and everyone gets the same rough treatment.

Interviewer: Women too?

P32, Male: Men and women, exactly.

(...) I think it's very hard to separate this
}

\begin{abstract}
from sexual harassment. At the same time he is the kind of guy who goes to the parties, getting drunk and dancing with the girls. Exactly where the whole case lies (...) I think it's very intricate. But I'm very sad to hear that he gets involved in this, because he should be an idol on this project (...). (Hasse \& Trentemøller 2008: 125).
\end{abstract}

Though regretted, the aggressive behaviour is in general an accepted aspect of the most idealised physicists in the Hercules culture. They are admired precisely because they know how to attack and are 'rough'.

Women are in Denmark not 'protected' from rough attacks by formal hierarchies or by a macho culture in which men tend to feel obliged to protect 'their' women. Consequently, our analysis shows that "femininity is an attribute to be overcome" (Vainio, 2008: 245) and sexual harassment is a contributory reason for women to leave science (Hasse \& Trentemøller, 2008: 120).

Caretakers are, as Hercules, aware of and engage in competition but contrary to Hercules, always as a collective effort to fight other groups. The way of competing in the culture types are closely linked to their understanding of scientific work. Hercules fights and work for himself in this extremely individualistic culture where all colleagues are potential competitors. Caretakers not only work in groups but pay much attention to social ties in everyday work. Consequently, their way of competing is not individual but collective and thus more open. By open we mean competition in which the contestants know and agree on who they are competing with and on what terms.

\footnotetext{
P71, Female: There is competition for getting the positions, because there are so many who would like a position. But there is not competition for money; it's
} 
more a feeling of congregating. We have often made a plan of what we would like to get, and then it's one person from the group who applies for one thing and another who applies for something else. We share that, so it's many people from the group who apply for money. There are never competitive applications. (ibid., 76)

The open and constructive competition is generally accepted in the Caretaker culture, though the men seem to talk more positively of competition in general as a factor that drives one to perform better than the women do.

P66, Male: [I]f the competition doesn't get out of control then I guess it is positive, because like everything else it helps speed up the process a bit and make people more focused, if they know that someone else is interested in something similar, working with something similar. (ibid., 75)

Hidden competition, however, is believed to corrupt collaboration and may hinder development in physics research. Moreover, as in-group competition (typically hidden) poses a destructive threat to the group structure it is strongly opposed.

Interviewer: Do you think that this competitiveness has influenced your career too?

P60, Female: Not really, because I always try to avoid those situations (...).[F]or me the most important thing is to establish a good relationship with the people I work with, everything else comes after, this is why I could not deceive the people I work with. And I am sure that at the same time they wouldn't do that to me. (ibid., 145)
In fact, compliance with the group is essential. On the one hand, this may have the effect that new creative solutions are not suggested or that inefficient ways of working are not challenged by members of a group. On the other hand, the familylike group formation seems to protect the members from blows either inside or outside the group. Moreover, we find that gender is rarely an element in competition, and femininity or sexuality does not seem to hinder scientific acknowledgement.

As mentioned, competition and ways of competing is a parameter that permeates the entire field of physics science-even for physicists who do not take part in competitions. This is also the case in the Worker Bee culture, which is characteristic of distant and powerful Herculean leaders who compete against each other in order to secure funding and prestige the given field while the average physicist worker steers clear of competition. Contrary to both the Caretaker and Hercules culture, the individual physicist in a Worker Bee culture is neither expected nor accepted as a player in these competitive games. Possibly for that reason some of our informants appear to be fully unaware of the competitive milieu:

Interviewer: But you said that physic - at least your work environment - wasn't very competitive?

P196, Male: (...) You see, the problem is, the question is actually very simple, why I never saw that competition, I didn't see it because it didn't take place on the spot, we were such a small unit and everyone was working on their area, because [the local boss] didn't fight here but with the foreign colleagues, right. You see, that's where the competition took place (...).(ibid., 174)

The portrait of a Worker Bee emerging from our data material is one who is uninterested 
in and somewhat scared of competition. Worker Bees appear to consider themselves as insufficiently equipped or not passionate enough to enter into, or win, fierce competition.

P15, Female: I have always thought that I do not have the courage to meet with them [indefinable competitors] because I am just different from them. (...) I am not made for doing research. I do not have this drive where you do not question it, where you just continue as if it is the best thing in the world. (...) I think it is (...) mainly because (...) I was a little, studious student at school and everything, but I just do not have the motivation or the interest or the elbows or the drive or the enterprise or - I easily let myself be knocked out. (...) [W] hen I get a new assignment I always think "Oh no, how will I manage that" and things like that, but then slowly I manage anyway. (ibid., 169)

Moreover, the formal hierarchy and division of labour in the Worker Bee culture sets a code of conduct in which the leaders take initiatives and decide on the direction of the scientific work while the employees take orders and follow instructions. If they act independently, or show signs of wanting to compete with members of the group they are likely to be punished by the leaders:

P196, Male: I have loads of ideas but they're not needed. Because, how to put it, I have some discords with [my boss] (...) And if [my boss] has that kind of attitude, like [being] the most important one in deciding, [my boss is] quite a smart person, but I'd say, [my boss'] attitude is, that I'm not the right guy and I don't feel like falling into arguments about that. (ibid., 184)
In contrast to the Hercules and to some extent the Caretaker culture, it is generally accepted in a Worker Bee culture if one has no intentions of striving for the top scientifically, but wishes to take up other roles in the research environment.

Female: [T]his upkeep of the measuring device net that are on my shoulders in such as large amount. It is because of, on the one hand that I'm not a very good researcher, but on the other hand that I'm so good at some of the practical side of things. And that has maybe allowed other researchers more freedom to just do research because I've been more in charge of these practical things (...) it has been easier for me, because I feel like that pressure of expectation isn't that great on me (...).(Vainio, 2008: 233)

Based on the UPGEM data material it is our assessment that because competition plays a relatively peripheral role for most Worker Bee physicists, they do not look for ways to fight each other and as a result gender is not something the physicists refer to as a possible element in competition. Overall, a number of other factors relating to competition such as the formal hierarchy, insecurity and observance of working hours (Hasse \& Trentemøller, 2008: 157-185) as well as a clear division between work and private life, the Worker Bee culture, like the Caretaker culture, do not tend to put gender before skills. Regardless of gender, anyone can count as a diligent Worker Bee and the women who advance are 'protected' by distinctions (titles, awards etc.).

When replacing nationality and gender on our data-material we find a cultural pattern of meaning supporting disgust for the extreme types of hidden competition in all countries. Hidden competition concerns 'stealing ideas', which can be more or less accepted: 
P79, Female: Well ugly things may happen there, when people steal each other's ideas [...] It's not very nice. You know who it is, but still they are allowed to run around out there. (ibid., 77)

But in the Danish context we can argue that hidden competition also excludes women in subtle ways which is not connected to their scientific capabilities but specifically relate to their gender-not least in relation to the acknowledged but not openly questioned acceptance of sexual harassment as a practice and aggression as a value. In the Danish data-material narratives of acts of sexual harassment that debase women are more frequent and aggressive competition as well than in the other country reports.

Summing up, on the basis of the national and culture contrastive analyses of competition we have found that though a number of the female stayers do express positive attitudes to open competition, they generally appear less willing to engage in competition or acknowledge the relevance of competition. Moreover, we have found that hidden competition bordering on harassment seems to affect the female interviewees more than the male and especially in the Danish context. As a result hidden competition contributes to the detected difference in men's and women's participation in physics.

\section{Cultural diversity in conceptions of creativity and innovation}

Many physicists see creativity as an important aspect of physics work and many of our interviewees answer that this aspect is what makes physics fun. In all the countries and fields, the physicists define physics as fun because it gives space for creative thinking. Some, however, also lament that the possibilities for creative thing diminish as experiments grow bigger and bureaucracy increases.
It also seems as if, as mentioned by Vainio, that male physicists are more prone to talk about "creativity, playfulness and the urge to experiment as a scientist's most important qualities, whereas no female interviewees remarked on these features" (Vainio, 2008: 237).
P229, Male: Because it [work] often requires this sort of, like I said before, like the enthusiasm of little boys regarding something. So then you can - to have certain kind of, I don't know if it's creativity or what. A little bit creativity, anyhow. And I believe that I possess that, too.(...) And I think that many of these guys possess a lot of exactly that quality (ibid., 237)

This is representative for the Finnish data and we also find it to be the case in the Estonian data where the national analysis points to three different styles of doing physics: 1) the physicist as a priest of truth 2) the physicist as a playful boy and 3) the physicist as a blacksmith (Velbaum, Lõhkivi \& Tina, 2008: 166). As indicated by the name, here too, creativity and innovative thinking is primarily associated with the male physicists (ibid. 175-180). This is as noted in the Italian report the stereotype of the physicist as a "male genius, creative and not understood, a person who 'lives in a world apart', absent-minded and shabby in appearance" (Ajello, Belardi \& Calafiore, 2008: 280).

We also find some differences in the national and scientific cultures. In Denmark, which is a predominantly Herculean culture, creativity is related to play (Hasse 2001), but also seem to be connected with competition, risk taking, self-promotion and making new discoveries no matter if they are useful for a wider public or not. 
P80, Male: [...]My areas of research have also always been relatively starry-eyed, and not directly useful for the industry. (...) I had an ambition of creating something big and become famous but not in any particular way.

Hercules is daring because for him this is what connects to being creative in rethinking physics. But risk is always connected to recognition and the chances of success.

P84, Male: [I] can work on risky projects, for example some crazy idea about how to do things better in fusion, which have a five percent chance of working out. Now I think that that would be well worth it, if it really has a five percent chance of working out. It is not well worth it for me now because doing something with a five percent likelihood of succeeding is not something you want to do when you are coming up for tenure. That gives you bad odds for giving tenure.

The creative ideas have to be weighed in relation to the risk of not being recognized as the best, which is so important to Hercules. It is only male physicists who connect invention and creativity with taking risks in science and risk is connected to personal gain.

But in the Caretaker culture, identified predominantly in the Italian academic work place cultures and in pockets of the Danish work place cultures, working on climate related physics and with relative many female researchers (Hasse \& Trentemøller, 2008: 129), physicists do not want to be creative at any prize. Several physicists refer to the destructive power of physics and the need for being morally responsible. The inventions of physics must be 'healthy' and physicists should consider how their scientific inventions might damage the world.
Scientists in Caretaker cultures worry about the risks. Even though they do not want politicians to make limits for the creative expansions of research, they clearly want the scientists themselves to take this responsibility:

P16, Female: $[\mathrm{T}]$ here is definitely this risk in research activity, I mean the fact that when you carry out a research you run the risk of getting certain things that might be used in a negative way, there is this danger; but I don't agree that this danger should limit research, hum, it should be a...[...] I think research should be able to limit its applications...[O]ne thing is to understand its potential and another thing is to actually [...] use it, you see...

Summing up, the national and culture contrastive analyses of competition and innovation and creativity have found that innovation is connected with risk-taking but that risks might be valued differently in the different work place cultures and that there is a gender dimension to how risk is valued. Female physicists might be more prone to be engaged in risks in relation to society and are thus in line with the values in the Caretaker culture whereas male physicists seem more personally occupied with risksand less concerned of consequences for society as such and are thus in line with the Hercules culture. These individual patterns of meaning seem to be supported by national cultures; physics in Italy, where we find many women, is more directed towards societal issues, whereas physicists in Denmark rather perceive society as a something of a necessary drag and the basic research is valued because it is connected to personal interest, playfulness and fun.

P66, Male: You can say that the things I have worked with have always been 
things that were -they were not useful in a narrow societal sense, not something that leads to great inventions or anything, but instead it has developed our more basic understanding of natural forces and how the universe works and-all the fun questions which everyone wants an answer to, and that is why they are so much fun to work with. So it has not so much been to make a difference, but more because I thought it was interesting (Hasse \& Trentemøller, 2008: 55).

Put differently, in Denmark and the Hercules culture at large, physicists experience an antagonistic relation between society and science, and science and humanities. Also, male researchers regret the new interest in disciplines like medicine because the same attention is not given to basic physics research.

P24, Male: I think it is a real pity. I think that in this society, there is a thoroughgoing current that you have to be a human sciences graduate. [I] $\mathrm{t}$ is fancier and more accepted than science. You have to do some of the soft subjects while this [physics], it is okay to say "I cannot".

In Italy, however, where we find the Caretaker culture to be dominant, we also find many women in 'useful' areas of physics. Moreover, we find that physics is naturally connected to humanities in this context (Hasse, 2008). Nevertheless, we also find the largest number of female particle physicists in this country, and particle physics as often been connected highly theoretical physics. This puzzle can be explained as particle physics in Italy can be related to the Caretaker and Worker Bee cultures, rather than the Herculean culture. Particle physics is, on the one hand a field that makes it possible to have a normal tranquil work life, if you work on the many calculation tasks related to the detectors at CERN and in other laboratories.

The many females connected with particle physics in Italy also ask for 'useful research':

P5, Female: I must say that there is a big crisis in this sector, a crisis of the ideas according to me because, on the one hand, we have been able to understand profoundly the mechanisms of the foundations of physics but, on the other hand, we are now studying things that have less impact on people's lives [...] and in my opinion physics has now very few impact on real life, it has not a strong impact on reality, as for example medicine or other technological branches have, these kinds of studies have an immediate application.

It is these turns which can open up for possibilities for female researchers, because the more 'useful' physics is now supported by the laboratories, as it will help them survive, but also because they find it more relevant than basic particle physics.

\section{P4, Female: [W]ell, someone who is doing this job might have a slight, a slight feeling, especially in basic physics, that something rather more useful might be done. [S] ome elementary particle physicists tried to approach medical physics, for example. I mean you know. Things that have some use for society.}

In the one pocket of Caretaker culture identified in the otherwise 'Herculean' culture in the Danish material (Hasse \& Trentemøller, 2008: 129), we find a female professor as a leader, who work on climate-changes and consider society, not as antagonistic, but as a natural part of a physicists work. 
P21, Female: I usually say to people that they should remember that it's also our job to deliver something to society, not just to keep everybody in here. If we can deliver such good things then we can be proud.

The women, even in the Herculean culture, prefer to work on useful topics, even if it means leaving academia:

P72, Female: "I researched what possibilities I had if I wanted to do something with physics and mathematics. And then there was Geophysics, which is, I don't suppose you could call it soft physics because it isn't, but more practical physics perhaps: practical and useful physics. And [...] there were more possibilities afterwards." (Hasse, Sinding \& Trentemøller, 2008: 65)

Summing up, in our overall analysis we find that women, regardless of national or scientific culture, to a higher degree than the men push for a more 'useful' physics. Furthermore this tendency promoted by the Caretaker-culture is more predominant in the Italian data, where we also in terms of numbers find the highest proportion of university employed female scientists. Additionally, female Caretakers emphasize that doing something for society is an important element in their research. Moreover, it is striking that many of the female physicists in general express either an interest in (bio)medicine or try to direct their work in physics towards the new interdisciplinary field of medical physics.

\section{Discussion and Conclusion}

In this article we have argued that gender emerges in seemingly gender neutral university work places in science through different cultural patterns of meaning, which form in- and exclusions of who can do science. This could be part of an explanation why many women are not reaching top-positions in science and also why we find a variation in the numbers of women in physics in different countries. The qualitative data-material we have had at our disposal is huge and complex and our research questions have made it necessary to leave out the a priory categorizations we find as organizing principle in much research on gender and culture. We have used the work place cultures as analytical tools to simplify the social reality embedded in our data, and this has enabled us to disclose the otherwise ambiguous mechanisms behind gendered in- and exclusion in physics. This tool can, as well as the cultural models we constructed, be criticized for oversimplifying the analysis and for overstraining what can be concluded from this analysis. Though we do not lean on a priori categorisations to the same extent as other comparative culture studies our method of culture contrast runs the risk of creating new overly simplifying researchbased organisations of the data-material.

Even so our analysis of the UPGEM-data gives rise to the question of why we find gender diversity in science. Furthermore in relation to STS-studies our analysis is relevant to the discussion of how the so called "epistemic cultures" are not just constructed by the scientists doing science and using instruments and apparatuses in particular ways (e.g. Knorr-Cetina, 1999), but also by the values of those in- or excluded from scientific practice.

Throughout our analysis of physics as culture we have found that there was a subtle relation between the actual number of male and female researchers in the work place environment, the type of research topics the physicists engage in and the research culture we have identified. To some extend this finding counters the notion of the work 
place culture as embedded in local national cultures. This line of questioning further calls for a deeper analysis of the cultural selection mechanisms of everyday life at universities, which might directly influence which type of scientific research is preferred to other types. As argued by Kristina Rolin, physicists should pay attention to these kinds of feminist analyses of gender ideology in the culture of physics "because these analyses reveal that the culture of physics is dominated by certain styles of doing science" (Rolin, 2008: 1120). Much more research is needed to understand the implications of the relation between culture, gender and physics.

Physics as a whole is in a transformation process going from what has been considered lofty, abstract and with no need for public interference to a discipline with emphasis on usefulness and, as pointed to elsewhere in our UPGEM-analysis, an emphasis on nanotechnology, biophysics and similar interdisciplinary research. To some extent, this change seems to mirror the development at universities in general from a more isolated 'disciplinary' knowledge production (mode 1) to a co-production of interdisciplinary applicable knowledge (mode 2) (Gibbons et al., 1994; Nowotny et al., 2001).

The mode 2 approach entails recognition of societal demands for useful research, but in our research the change is met with different responses in national and scientific cultures and calls forth new contradictions and reactions in local work places (Hasse \& Trentemøller, 2008: 126). The movement from mode 1 to mode 2 seems to draw more women into the discipline of physics. But the work place culture also seems to play an important role in relation to how creativity and the new usefulness of research are viewed as values by the physicists. As this research in general is opening up towards engagements between science and society, a Herculean culture, which thrives confined in the physics bubble, prefers to exclude researchers who are interested in usefulness. Though it can be considered a necessary evil to take societal demands into consideration, especially the male researchers take pride in placing their research within the physics bubble with no use for society-as this is connected to being creative, playful, willing to take risks and successful in the Hercules culture. In the Caretaker culture we find many women who work in 'useful' fields of science, such as climate science, geophysics and medical physics. In some cases the women can be seen as 'pushing science from 'lofty' high energy physics towards medical physics (as in particle physics), but also male physicists acknowledge the importance of relations with society in a Caretaker culture and the considerations of not taking risks, which can harm society.

In the Danish 'pocket' examples we see that the physicists retain their love for physics while they emphasize the usefulness of their work, their strong feeling of group solidarity and their being able to combine work and family life (ibid., 129). Male physicists in general seem more prone to 'guard' the borders of science as they are more "actively involved with the boundary work in their field of science, whereas female physicists either were not concerned about the boundaries or ignored them" (Hasse \& Trentemøller, 2008: 240) or, we could add, transgress boundaries by placing themselves in interdisciplinary field of 'useful research'.

The few research environments with relatively large numbers of female physicist researchers seem to be interested in specific topics no matter in what country we find them. On the other hand, the ideals of certain work place cultures seem to thrive better in some national contexts than others (e.g., Hercules in Denmark). It is thus very difficult to decide, from our material, 
whether gender emerges in work place cultures or whether it is the national gender constitutions, which makes particular work place cultures likely to emerge. In any case we have found a connection between epistemic cultures and the values, norms and traditions of work place cultures, which again can be connected with the actual number of female scientists and the topics they consider relevant for the pursuit of scientific knowledge. On the basis of the UPGEM data material, we can thus point to a convergence between the number of women in physics, the given work place culture and the scientific topics studied in universities as work places. It is on the basis of this argument that we can ask whether women's preferences for specific research topics, the creative unfolding of these and a particular preference for research environmental without too much hidden competition are in fact tied to the number of women in research cultures.

\section{Notes}

1 A number of other reports also illustrate this diversity (see for instance the homepage of the International Union of Pure and Applied Physics: http://www. iupap.org and the Working Group on Women in Physics: http://www.if.ufrgs. br/ barbosa/women.html). A consistent pattern seems to be that eastern and southern European countries have a higher score in percentage of women working as professionals in physics.

2 UPGEM was financed by EU's 6.th framework programme in the period 20052008.

3 This database included interviews from all five participating countries: Denmark, Poland, Italy, Estonia and Finland. For a detailed description of method, methodology and interview-guide see Hasse, Trentemøller and Sinding, 2008.
4 Even when leavers thus left voluntarily and for many different reasons, "leaving" is in our analysis always connected with work place cultures creating cultural potentials for staying or reasons for leaving. In the Italian data some leavers, who have left university based physics research in their own country but continued in countries considered to have better work place conditions for doing research, are also included.

5 We identified many examples of cultural models in physics. For a more thorough introduction to the concept of 'cultural models' and our work with this approach see Hasse \& Trentemøller, 2008, 42 ff.)

${ }_{6}$ The three work place cultures in some ways connect to what Mary Douglas has described as the 'grid-group' theory in organizations (1970), but being researchbased also our model a much more refined analytical tool which in some ways, which we cannot present in detail, contradicts Douglas' model.

7 The concept of directional forces is further explained in relation to cultural models in Strauss \& Quinn (1997).

8 We will not call these ideal types 'stereotypes. They are not explicitly referred to by our informants but rather form the background knowledge of how they perceive the values, norms and traditions of an ideal physicist at their work place. They might not be referred to as actual practice, but what informants believe it is generally considered ideal to strive for as physicists.

9 For more details on the empirical data and methods of collecting and/or processing data, see Hasse and Trentemøller, 2008: 23-50, Hasse and Trentemøller, 2009 .

10 This analysis is not contradicting an Italian analysis of the many problems for female researchers in Italy. As we noted in the beginning of this article women in all 
countries have severe problems 'climbing the ladder' (Ajello, Belardi, Calafiore, 2008).

11 We found huge differences between the Estonian and Polish data (Velbaum, Lõhkivi \& Tina, 2008, Chudzicka-Dudzik, Diekmann, Miazek, and Oleksy, 2008). Poland has many female physicists compared to Estonia yet we found indications of the same type of work place culture in both countries. Finland seems to be a mix of the three work place cultures and have more female physicists than Denmark, but less than Denmark.

12 Some of the quotations have been published in the UPGEM-reports and appear here with the relevant references. Others are presented here for the first time and only appear with the number of the interview and the gender of the interviewed.

\section{References}

Ajello, A.M., C. Belardi \& G. Calafiore (2008) 'Italian National Report', in Hasse, C., Sinding, A.B. and Trentemøller, S. (eds), Draw the Line! University as workplaces for male and female researchers in Europe (Tartu: Tartu University Press): 263-364.

Alvesson, M. \& P. O. Berg (1992) Corporate Culture and Organizational Symbolism: An Overview (Berlin: Walter De Gruyter Inc.).

Barad, K. (2001) ' $\operatorname{Re}($ con)figuring space, time, and matter', in M. DeKoven (ed), Feminist locations: Global and local, theory and practice (New Brunswick: Rutgers University Press).

Chudzicka-Dudzik, P., A. Diekmann, M. Miazek \& E. Oleksy (2008) 'UPGEM National Report Poland, in Full Collection of National Reports. Universities as workplaces for male and female researchers in Europe (362441). Retrieved August $14^{\text {th }}$ at http://
www.dpu.dk/Everest/Publications/ Subsites/UPGEM/20080812161221/ CurrentVersion/Full\%20Collection\%20 of\%20National\%20Reports_b.pdf

Douglas, M. (1970) Natural Symbols. Explanations in Cosmology (New York: Pantheon Books).

Etzkowitz, H. \& L. Leydesdorff (2000) 'The dynamics of innovation: from National Systems and " Mode 2 " to a Triple Helix of university-industry-government relations.' Research Policy. 29(2): 109123.

Geertz, C. (2001) Available light: anthropological reflections on philosophical topics (Princeton, Oxford: Princeton University Press).

Gibbons, M., C. Limoges, H. Nowotny, S. Schwartzman, P. Scott \&M. Trow (1994) The New Production of Knowledge: The Dynamics of Science and Research in Contemporary Societies, (London: Sage). Haraway, D. (1997) Modest-Winess, Second-Millenium: Female-man Meets Oncomouse: Feminism and Technoscience (London: Routledge).

Haraway, D. (1991) 'Situated Knowledges: The Science Question in Feminism and the Privilege of Partial Perspective,' in D. Haraway: Simians, Cyborgs and Women. The Reinvention of Nature (London: Free Association Books): 183-203.

Harding, S. (1986) The Science Question in Feminism (Cornell University Press).

Harding, S. (2006) Science and social inequality. Feminism and postcolonial studies. (Chicago: University of Illinois Press).

Hasse, C. (2002) 'Gender diversity in play with Physics. The Problem of Premises for Participation in Activities' Mind, Culture and Activity 9(4): 250-270.

Hasse, C. \& S. Trentemøller (2009) 'The Method of Culture Contrast' Qualitative Research in Psychology 6(1/2): 46 - 66 
Hasse, C. \& S. Trentemøller (2008) Break the Pattern. A critical enquiry into three scientific workplace cultures: Hercules, Caretakers and Worker Bees (Tartu: Tartu University Press).

Hasse, C. \& S. Trentemøller, A.B. Sinding (eds) (2008) Draw the Line! Universities as workplaces for male and female researchers in Europe (Tartu: Tartu University Press).

Hofstede, G. (1980) Culture's Consequencies (London: Sage).

Holland, D \& N. Quinn (eds) (1987) Cultural models in language and thought (Cambridge, UK: Cambridge University Press).

Ihde, D. (2002) Bodies in Technology (Minneapolis, MN: University of Minnesota Press).

Keller, E. F. (1985) Reflections on Gender and Science (New Haven: Yale University Press).

Knorr-Cetina, K.D. (1999) Epistemic Cultures: How the Sciences Make Knowledge (Cambridge: Harvard University Press).

Latour, B. (2005) Reassembling the Social: An Introduction to Actor-NetworkTheory (Oxford: Oxford University Press).

Longino, H. (2002) The fate of knowledge (Princeton: Princeton University Press)

Martin, J. (2002) Organizational culture: mapping the terrain (London: Sage Publication).

McSweeney, B. (2002) 'Hofstede's model of national cultural differences and their consequences: A triumph of fait -a failure of analysis', Human Relations 55: 89-118.

Merchant, C. (1989) The Death of Nature: Women, Ecology and the Scientific Revolution (San Francisco: Harper Collins).

Nowotny, H, P. Scott, and M. Gibbons (2001) Re-Thinking Science: Knowledge and the Public in an Age of Uncertainty (Cambridge: Polity Press).
Rolin, K. (2006) 'Gender and physics: feminist philosophy and science education', Science \& Education, 17(10): 1111-1125.

Rouse, J. (1992) 'What are Cultural Studies of Scientific Knowledge?' Configuration 1(1): 57-94.

Schein, E. (2004) Organizational Culture and Leadership, 3rd ed. (San Francisco: Jossey-Bass).

Smircich, L. (1983) 'Concepts of Culture and Organizational Analysis' Administrative Science Quarterly, 28(3): 339-358.

Strauss, C \& Quinn, N. (1997) A Cognitive theory of cultural meaning (Cambridge, UK: Cambridge University Press).

Strauss, C. (1992) 'Models and motives', in R. D'Andrade \& C. Strauss (eds), Human Motives and Cultural Models (Cambridge: Cambridge University Press):1-20

Svinth, L. (2008) 'Women in physical science', in C. Hasse, S. Trentemøller and A.B. Sinding (eds), Draw the Line! International Conference, Copenhagen 2008. Papers, proceedings and recommendations (Tartu: Tartu University Press): 19-43. .

Traweek, S. (1992) 'Border Crossings: Narrative Strategies in Science Studies and among Physicists in Tsukuba Science City, Japan,' in Pickering, A. (ed), Science as Practice and Culture (Chicago, London: University of Chicago Press): 429-465.

Traweek, S. (1988) Beamtimes and lifetimes. The world of high energyphysicists (London: Harvard University Press).

Vainio, J. (2008) 'UPGEM National Report Finland', in C. Hasse, A.B. Sinding and S.

Trentemøller (eds). Draw the Line! University as workplaces for male and female researchers in Europe ) (Tartu: Tartu University Press): 213-262.

Velbaum, K., E. Lõhkivi and M.-L. Tina (2008) 'The Estonian National Report', in 
Hasse, C., A. Sinding and S. Trentemøller (eds) Draw the Line! Universities as workplaces for male and female researchers in Europe .(Tartu: Tartu University Press): 137-213.

Watson-Verran, H., \& D. Turnbull (1995) 'Science and other indigenous knowledge systems', in S. Jasanoff, G. Markle, J. Petersen, \& T. Pinch (eds), Handbook of science and technology studies (Thousand Oaks, CA: Sage Publications): 115-139.

\section{Documents}

European Commission (2005). 'Women and Science-Excellence and Innovation. Gender Equality in science'. (Commission staff working document). Luxembourg: Office for official publications of the European communities. Retrieved June $9^{\text {th }}, 2008$ from the Europe server at http:// ec.europa.eu/research/science-society/ pdf/documents_women_sec_en.pdf

European Commission (2006). SHE-figures 2006. Women and Science Statistics and Indicators. Luxembourg: Office for official publications of the European communities. Retrieved August $26^{\text {th }}$, 2008 from the Europe server at http:// ec.europa.eu/research/science-society/ pdf/she_figures_2006_en.pdf
European Commission (2008). Mapping the Maze: Getting more women to the top in research. Luxembourg: Office for official publications of the European communities. Retrieved May $9^{\text {th }} 2008$ from the Europe server at http:// ec.europa.eu/ research/science-society/ document_library/pdf_06/mapping-themaze-getting-more-women-to-the-topin-research_en.pdf

Cathrine Hasse

Department of Learning,

The Danish School of Education, University of Aarhus

Tuborgvej 1642400

Copenhagen NV Denmark

caha@dpu.dk

Stine Trentemøller

Department of Learning, The Danish School of Education, University of Aarhus

Tuborgvej 1642400

Copenhagen NV Denmark

STINET@dpu.dk 